\title{
Phenotypic variability of natural and cultivated populations of Oreochromis niloticus from Haut Sassandra region (Côte d'Ivoire)
}

\author{
*YOBOUE Ahou Nicole ${ }^{1}$, BOUSSOU Koffi Charles ${ }^{2}$, KONAN Kouassi Sylvain ${ }^{3}$, KONAN \\ Koffi Félix ${ }^{4}$, ADEPO-GOURENE Abouo Béatrice ${ }^{5}$ \\ 1 \\ 1*, 2, 4: Department of Environment, University Jean Lorougnon Guédé, P.O Box 150 Daloa, Côte d'Ivoire. \\ ${ }^{3}$ Oceanological Research Center, Department of Aquaculture, Abidjan, Côte d'Ivoire, PoBox V 18 Abidjan. \\ ${ }^{5}$ Nangui Abrogona University, Laboratory of Genetic, Abidjan, Côte d'Ivoire, 02 PoBox 801 Abidjan 02 \\ * Corresponding authors, email: ayobouen@yahoo.fr; Tel: 22508047314
}

Keywords: Oreochromis niloticus, phenotypic characterization, Haut-Sassandra region, metric and meristic characters.

Publication date 30/09/2019, http://www.m.elewa.org/JAPS

$1 \quad$ ABSTRACT

The phenotypic characterization of four populations of Oreochromis niloticus (Linnaeus, 1758) from the Haut-Sassandra region was carried out using 147 specimens. Among them, 39 were from the natural environment (Sassandra River) and 108 from three fish farms in the town of Daloa. The body weight, sixteen (16) metric characters and fifteen (15) meristic characters recorded on each individual made it possible to analyze the phenotypic variability of the four populations. Twenty-eight (28) on the 31 morphometric characters studied differentiated populations $(P<0.001)$. Based on these 28 characters, Principal Correspondence Analysis (PCA) and Hierarchical Classification Analysis (HCA) grouped the individuals into two groups, a group consisting of Guessabo and PK 12(Kilometer 12 fish farm located at the end of the city of Daloa) specimens and the other group consisting of APDRACI and Quartier Manioc (two fish farms in the city) individuals. Six morphometric characters (PrAL. IOD. LDF. DAL. AFL and SsL) were the most relevant in the discrimination of these two groups. Discriminant factor analysis (DFA) has also classified these populations into two clusters identical to those of the PCA and the HCA. The brood stocks of PK 12 farm is morphologically identical to specimens of the natural environment (Guessabo). The waters of the PK 12 farm have similar characteristics to the natural environment. The PK 12 farm compared to the others (APDRACI and Quartier Manioc) would be better managed.

2 INTRODUCTION

In Côte d'Ivoire, fish account for more than $50 \%$ of animal protein consumption and fish consumption is around $15 \mathrm{~kg} /$ capita / year (FAO, 2016). National fish production from fish farming in 2012 was estimated at only 3720 tons for a total fish production of 75611 tons, while the annual demand for fish resources was estimated at about 300000 tons / year (FAO, 2014). To raise the level of aquaculture production, several fisheries and aquaculture 
development projects have been implemented. Despite these efforts, the fish farming sector has not yet reached a viable economic dimension in Côte d'Ivoire in the agricultural production system. In order to compensate this deficit, tilapia Oreochromis niloticus (Linnaeus, 1758) rearing has been popularized, this species having interesting characteristics in aquaculture, good nutritional quality (Kestemont et al., 1989) and widely distributed on all continents (Azaza 2009, Dhraief et al., 2010). However, fish farmers of this species report recurrently a deficit of growth. Indeed, with the socio-political crisis experienced by Côte d'Ivoire in recent decades, the lack of control of aquaculture by national guardianship structures has fostered uncontrolled exchanges

\section{MATERIAL AND METHODS}

3.1 Sample collection: Specimens of Oreochromis niloticus were collected from September 2018 to February 2019 from 3 farms located in Daloa City and in Sassandra River near Guessabo City (Figure 1). Two farms were into the town, "Quartier Manioc and APDRACI. The third farm, PK12 is located $12 \mathrm{Km}$ of brood stocks of different strains to such an extent that it is almost impossible today to identify the different strains cultivated in Côte d'Ivoire. To address this concern, it is necessary to carry out population biological studies in order to identify populations or strains. This type of study relies, most often, on genome analysis and examination of the external appearance of individuals (Kraiem, 1994). The Haut-Sassandra region is one of the major fish production areas in Côte d'Ivoire. The present study therefore proposes to determine the phenotypic variability of different brood and natural populations of Oreochromis niloticus from this region on the basis of meristic and metric characters study.

from Daloa city. A total of 147 individuals were collected in which 45 were from Quartier Manioc, 31 from APDRA-CI, 32 from PK12 and 39 from Guessabo. The samples from Guessabo in river were caught by gillnets and those from farms were captured from ponds.

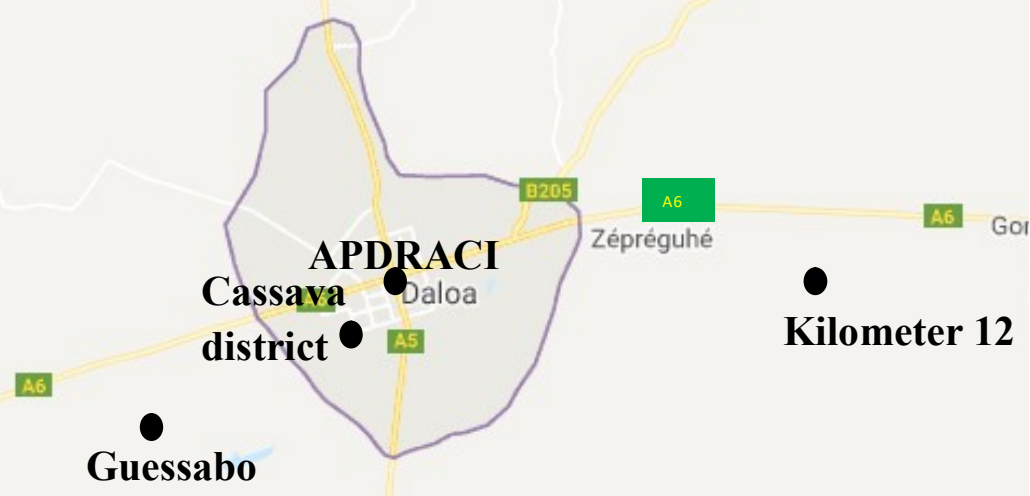

Map data $\oplus 2019 \mathrm{G}$

Figure 1: Map of Daloa city showing sampling sites of O. niloticus specimens; Sites of sampling 
Sixteen (16) metric characters were measured on each specimen and 15 meristic characters were obtained by counting.

\subsection{Morphometric analyses}

3.2.1 Metric characters: Each individual was labelled with a specific code for identification. A digital camera (Sony, Japan) was used for capturing the digital images. Morphometric variations among populations were assessed through geometric methods (Zelditch et al., 2004). Sixteen morphometric variables were selected as inter landmark distances for $O$. niloticus based on 10 homologous anatomical landmarks as shown in Figure 2. The first two characters (TL and SL) were measured using an ichthyometer. Measurements were based on a truss network protocol (Bookstein et al., 1985). The derivation of truss distances from the digital images of specimens was done using a combination of three software platforms: tpsutil, tpsdig (Rohlf, 2004, 2006) and PAlentologial STatistics (PAST; Hammer et al., 2001).

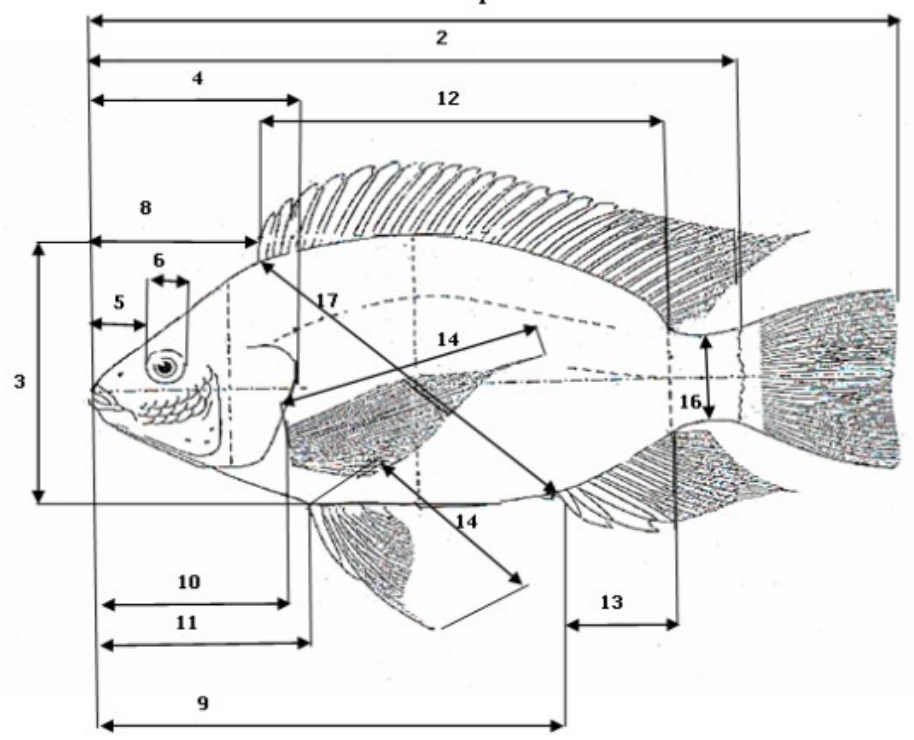

Figure 2: Measurements made on specimens: 1 : total length (TL), 2 : standard length (SL), 3 : body height (BH), 4 : length of the head (LH ), 5 : Muzzle length (ML), 6 : interorbital diameter (IOD), 7 : predorsal length (PrDL), 8 : pre-anal length (PrAL), 9 : prepectoral length (PrPL), 10 : prepelvic length (PrPeL), 11 length of dorsal-fin base (LDF), 12 anal fin length (AFL), 13 length of pectoral fin (LPF), 14 : length of pelvic fin (LPeF), 15 : caudal peduncle height (CPH), 16 : dorso -anal length (DAL).

3.2.2 Meristic characters: Fifteen meristic characters were counted on each specimen. These counts were the number of anal fin rays (AR), number of thorny rays at anal fin (tRA); number of soft rays at anal fin (sRA), number of dorsal fin rays (DR), number of thorny rays at dorsal fin (tRD), number of soft rays at dorsal fin (sRD), number of scales on superior lateral line (SsL), Number of scales on lower lateral line (SIL); number of pectoral fin rays (PR), number of teeth on superior jaw ( $\mathrm{Ts} J)$, number of teeth on lower jaw ( $\mathrm{TlJ})$, number of teeth two tips on superior jaw (TTsJ), number of teeth two tips on the lower jaw (T'TlJ), 
number of pelvic fin radius (PelR) and the number of gill rakers on the first branchial arc (N. branchios).

3.2.3 Statistical analyzes: Morphometric data have been standardized to avoid size variations due to age differences between individuals. This standardization is based on the allometric relationship between the morphological data and the size of the fish. In order to eliminate any size effect in the data set, an allometric formula was used to remove length effects in the samples: $\mathrm{SM}=\mathrm{M} 0$ (SL / L0) ${ }^{\text {b }}$ (Thorpe, 1976, Ihssen et al., 1981, Elliott et al., 1995, Hurlbut and Clay, 1998). SM = standardized measurement; $\mathrm{M} 0=$ measure of the character; SL = average of standard lengths of all specimens of all populations; L0 = standard length of the specimen. The value of $b$ was estimated for each character following the allometric growth equation: $\mathrm{M}=\mathrm{aL}^{\mathrm{b}}$. Coefficient $b$ was evaluated as the slope of regression of $\log _{10} \mathrm{M}_{0}$ on $\log _{10} \mathrm{~L}_{0}$ using all fishes in each group (Lleonart et al., 2000; Ferrito et al., 2007). After the standardization of the metric data, the entire data matrix (metric and meristic) was previously submitted to a MANOVA to verify the significance of all the parameters. The processing of these metric and meristic data was performed using elementary statistics, oneway analysis of variance (ANOVA 1) and multivariate analyzes. In terms of descriptive

\section{RESULTS AND DISCUSSION}

\subsection{Results}

4.1.1 Phenotypic variability of populations: Of the 31 characters, the number of thorny rays at anal fin (tRA) did not vary (3) among individuals, so it was deleted from the list of variables. After the allometric transformation, there was no significant correlation between standard length and the morphometric measurements, which indicate that size effect was removed effectively from the data with the allometric transformation. Multivariate analysis of variance (MANOVA) statistics, the mean, standard deviation, range (minimum-maximum) and coefficient of variation were calculated. The coefficient of variation $(\mathrm{CV})$ was calculated using the following formula:

$\% \mathrm{CV}=$ (standard deviation $/$ mean $) \times 100$ (Zarr, 1999). It makes it possible to evaluate the variations of a character within the populations. When $\% \mathrm{CV} \leq 10 \%$, the population is very homogeneous; CV $>10 \%$ the population is heterogeneous.

ANOVA was performed to highlight the parameters that express variability between different populations. Multivariate statistics performed included Principal Component Analysis (PCA), Discriminant Factor Analysis (DFA), and Hierarchical Classification Analysis (HCA). PCA has been used to differentiate populations and identify the morphometric variables that contribute most to their separation. These variables, integrated in a second time to discriminant analyzes, allowed to highlight the most efficient ones, to illustrate the differences and similarities between constituted groups and to optimize the existing variables between them. Hierarchical classification analysis (HAC) was undertaken to assess morphological similarity between populations (Ferrito et al., 2007). All these treatments were performed using STATISTICA program (StatSoft, version 7.1).

across the four populations showed a highly significant difference $(F=9.07, P<0.001)$ between populations. The ANOVA revealed that this difference is due to 28 out of 30 analyzed descriptors $(P<0.05)$ (Table 1$)$. This is the number of ML, LH, PrDL, PrAL, PrPL, PrPeL, IOD, LDF, DAL, BH, CPH, AFL, LPF, LPeF, TL, SL, DR, tRD, sRD, AR, sRA, PR, SsL, SiL, TsJ, TTsJ, TTij and N. branchios. The two non-significant characters $(\mathrm{LPeF}$ and TlJ) were extracted from the database for other analyzes. Comparison of the descriptive 
statistical data showed that the highest averages of the metric parameters analyzed in addition to the weight were obtained in the natural population of Guessabo (Table 1). At the three farms, the high values of the metric descriptors in addition to the weight were recorded in PK 12 (Table 1). Descriptive analysis of all populations showed that twenty (20) of the 28 variables overall showed high variability $(\mathrm{CV}>$ $10 \%$ ) in populations (Table 1). All metric characters measured had the highest $\mathrm{CV}$ values. The interorbital diameter (IOD) gives the highest value of the coefficient of variation $(\%$ $\mathrm{CV}=98.29 \%$ ).

Table 1: Mean values of the 31 morphological parameters measured.

\begin{tabular}{|c|c|c|c|c|c|c|c|c|c|}
\hline & $\begin{array}{l}\text { Kilo } 12 \\
\text { Mean } \pm \text { SD }\end{array}$ & $\begin{array}{l}\text { APDRACI } \\
\text { Mean } \pm \text { SD }\end{array}$ & $\begin{array}{l}\text { Guéssabo } \\
\text { Mean } \pm \text { SD }\end{array}$ & $\begin{array}{l}\text { Cassava D } \\
\text { Mean } \pm \text { SD }\end{array}$ & $\begin{array}{l}\text { Overall mean } \\
\pm \text { SD }\end{array}$ & Min & $\operatorname{Max}$ & CV\% & $P$ \\
\hline ML & $1.05 \pm 0.28$ & $0.81 \pm 0.20$ & $1.01 \pm 0.24$ & $0.93 \pm 0.23$ & $0.955 \pm 0.254$ & 0.488 & 1.527 & 26.590 & $<0.001$ \\
\hline $\mathrm{HL}$ & $4.38 \pm 0.71$ & $3.38 \pm 0.60$ & $4.35 \pm 0.77$ & $3.69 \pm 0.64$ & $3.950 \pm 0.794$ & 2.464 & 6.634 & 20.101 & $<0.001$ \\
\hline PrDL & $6.12 \pm 0.67$ & $4.41 \pm 0.76$ & $6.17 \pm 0.84$ & $4.76 \pm 0.67$ & $5.358 \pm 1.068$ & 3.079 & 8.531 & 19.932 & $<0.001$ \\
\hline PrAL & $11.87 \pm 1.52$ & $7.84 \pm 1.58$ & $11.87 \pm 1.86$ & $8.47 \pm 1.15$ & $9.983 \pm 2.390$ & 2.972 & 16.328 & 23.940 & $<0.001$ \\
\hline PrPL & $5.10 \pm 0.79$ & $3.99 \pm 0.73$ & $5.08 \pm 0.89$ & $4.17 \pm 0.65$ & $4.577 \pm 0.911$ & 2.932 & 7.565 & 19.903 & $<0.001$ \\
\hline PrPeL & $6.29 \pm 0.81$ & $4.51 \pm 0.69$ & $6.27 \pm 0.98$ & $4.83 \pm 0.71$ & $5.465 \pm 1.131$ & 3.307 & 9.001 & 20.695 & $<0.001$ \\
\hline IOD & $0.93 \pm 0.16$ & $1.56 \pm 2.41$ & $0.96 \pm 0.21$ & $0.87 \pm 0.15$ & $1.052 \pm 1.034$ & 0.490 & 10.31 & 98.288 & $<0.05$ \\
\hline LDF & $9.17 \pm 1.34$ & $2.90 \pm 1.33$ & $9.09 \pm 1.51$ & $6.23 \pm 0.98$ & $7.496 \pm 2.045$ & 2.897 & 12.09 & 27.281 & $<0.001$ \\
\hline DAL & $9.48 \pm 1.27$ & $6.03 \pm 1.39$ & $9.47 \pm 1.49$ & $6.25 \pm 0.89$ & $7.763 \pm 2.08$ & 2.470 & 12.482 & 26.794 & $<0.001$ \\
\hline BH & $6.93 \pm 0.88$ & $4.54 \pm 1.04$ & $6.95 \pm 1.05$ & $4.75 \pm 0.65$ & $5.764 \pm 1.451$ & 3.082 & 9.500 & 25.183 & $<0.001$ \\
\hline $\mathrm{CPH}$ & $2.35 \pm 0.34$ & $1.58 \pm 0.32$ & $2.29 \pm 0.32$ & $1.61 \pm 0.23$ & $1.947 \pm 0.470$ & 1.107 & 2.930 & 24.173 & $<0.001$ \\
\hline AFL & $2.86 \pm 0.39$ & $2.29 \pm 1.46$ & $2.82 \pm 0.45$ & $2.02 \pm 0.37$ & $2.473 \pm 0.838$ & 1.161 & 7.901 & 33.885 & $<0.001$ \\
\hline LPF & $6.08 \pm 0.95$ & $3.98 \pm 1.01$ & $6.10 \pm 1.04$ & $4.12 \pm 0.66$ & $5.043 \pm 1.362$ & 0.937 & 8.340 & 27.008 & $<0.001$ \\
\hline $\mathrm{LPeF}$ & $4.73 \pm 0.69$ & $2.74 \pm 0.70$ & $4.71 \pm 0.77$ & $3.23 \pm 0.63$ & $3.845 \pm 1.105$ & 1.716 & 6.165 & 28.738 & $<0.001$ \\
\hline TL & $16.70 \pm 2.67$ & $12.73 \pm 2.31$ & $19.21 \pm 2.36$ & $13.49 \pm 2.11$ & $15.546 \pm 3.505$ & 9.125 & 23.452 & 22.546 & $<0.001$ \\
\hline SL & $13.24 \pm 2.28$ & $9.98 \pm 1.77$ & $14.97 \pm 1.85$ & $10.41 \pm 1.55$ & $12.146 \pm 2.772$ & 7 & 19.3 & 22.823 & $<0.001$ \\
\hline DR & $27.75 \pm 0.62$ & $27.71 \pm 0.69$ & $29.08 \pm 0.84$ & $28.24 \pm 0.88$ & $28.24 \pm 0.947$ & 27 & 31 & 3.353 & $<0.001$ \\
\hline tRD & $16.59 \pm 0.50$ & $16.32 \pm 0.47$ & $16.95 \pm 0.22$ & $16.53 \pm 0.50$ & $16.61 \pm 0.489$ & 16 & 17 & 2. 944 & $<0.001$ \\
\hline sDR & $11.19 \pm 0.40$ & $11.39 \pm 0.56$ & $12.15 \pm 0.87$ & $11.73 \pm 0.89$ & $11.65 \pm 0.816$ & 11 & 15 & 7.004 & $<0.001$ \\
\hline $\mathrm{AR}$ & $11.59 \pm 0.71$ & $11.12 \pm 0.72$ & $12.10 \pm 0.85$ & $11.47 \pm 0.79$ & $11.591 \pm 0.84$ & 9 & 13 & 7.21 & $<0.001$ \\
\hline sRA & $8.59 \pm 0.71$ & $8.13 \pm 0.62$ & $9.10 \pm 0.85$ & $8.53 \pm 0.79$ & $8.61 \pm 0.82$ & 7 & 10 & 9.523 & $<0.001$ \\
\hline PR & $11.66 \pm 0.94$ & $9.52 \pm 1.12$ & $12.77 \pm 1.22$ & $11.22 \pm 1.40$ & $11.367 \pm 1.643$ & 7 & 15 & 14.454 & $<0.001$ \\
\hline SsL & $22 \pm 0.72$ & $21.22 \pm 0.72$ & $21.90 \pm 0.82$ & $21.35 \pm 1.35$ & $21.612 \pm 1.023$ & 18 & 25 & 4.733 & $<0.001$ \\
\hline SlL & $14.87 \pm 1.01$ & $12.81 \pm 0.98$ & $14.85 \pm 1.69$ & $12.82 \pm 2.94$ & $13.803 \pm 2.195$ & 9 & 18 & 15.902 & $<0.001$ \\
\hline TsJ & $64.28 \pm 6.18$ & $64.13 \pm 4.50$ & $71.18 \pm 5.24$ & $58.29 \pm 5.70$ & $64.245 \pm 7.279$ & 45 & 80 & 11.33 & $<0.001$ \\
\hline TTsJ & $61.34 \pm 6.27$ & $60.29 \pm 4.17$ & $65.67 \pm 6.19$ & $53.93 \pm 6.21$ & $60.00 \pm 7.337$ & 42 & 77 & 12.229 & $<0.001$ \\
\hline TTlT & $53.44 \pm 3.74$ & $50.26 \pm 3.79$ & $53.05 \pm 4.48$ & $52.33 \pm 4.90$ & $52.326 \pm 4.441$ & 38 & 62 & 8.487 & $<0.05$ \\
\hline N.branchios & $27.62 \pm 1.34$ & $26.74 \pm 1.67$ & $28.74 \pm 1.55$ & $28.27 \pm 1.14$ & $27.931 \pm 1.582$ & 25 & 32 & 5.664 & $<0.001$ \\
\hline
\end{tabular}

$\mathrm{SD}=$ standard deviation

\subsubsection{Principal Component Analysis} (PCA): The examination of the matrix of factorial loadings retained the first axis $(50.28 \%)$ and the second axis $(8.81 \%)$ which explained $59.09 \%$ of the total variance (Table 2 ) for the Principal Component Analysis (PCA). Thirteen (13) characters were relevant for the explanation of morphologic variability among the populations (Table 2, Figure 3). These thirteen metric variables were defined by the first axis. These are length of the head (LH), predorsal length (PrDL), pre-canal length
(PrAL), prepectoral length (PrPL), prepelvic length (PrPeL), dorsal fin base length (DFL), dorsal -anal length (DAL), body height $(\mathrm{BH})$, caudal peduncle height $(\mathrm{CPH})$, pectoral fin length (PFL), pelvic fin length (PeL), total length (TL) and standard length (SL). These parameters are negatively correlated to the first principal component. None characters are correlated with the second principal component. The scatter plot of two first components presented four polygons $(1,2,3$ and 4) that corresponded to the distribution of 
the four populations. Two clusters stand out more or less. The first cluster corresponding to the populations of PK12 and Guessabo, (the polygons 1 and 3) is distributed on the negative side of the axis 1 (Figure 4). The specimens in this cluster show positive correlation with the
13 morphometric variables previously cited compared to individuals from the second cluster constituted largely of individuals from APDRACI and (Quartier Manioc located in the positive side of the first principal component.

Table 2: Contribution of factorial axis and correlation of variables to axis factorial

\begin{tabular}{|c|c|c|}
\hline & Axis 1 & Axis 2 \\
\hline \multirow{3}{*}{$\begin{array}{l}\text { Cumul eigen value } \\
\text { Cumul \% }\end{array}$} & 14.07 & 16.54 \\
\hline & 50.28 & 8.81 \\
\hline & 50.28 & 59.09 \\
\hline HL & -0.853 & 0.142 \\
\hline PrDL & -0.953 & 0.078 \\
\hline PrAL & -0.969 & 0.061 \\
\hline PrPL & -0.872 & 0.139 \\
\hline PrPeL & -0.961 & 0.109 \\
\hline LDF & -0.941 & 0.016 \\
\hline DAL & -0.959 & 0.160 \\
\hline BH & -0.945 & 0.207 \\
\hline $\mathrm{CPH}$ & -0.921 & 0.198 \\
\hline LPF & -0.915 & 0.173 \\
\hline LPeF & -0.919 & 0.071 \\
\hline TL & -0.896 & -0.096 \\
\hline SL & -0.908 & -0.052 \\
\hline
\end{tabular}




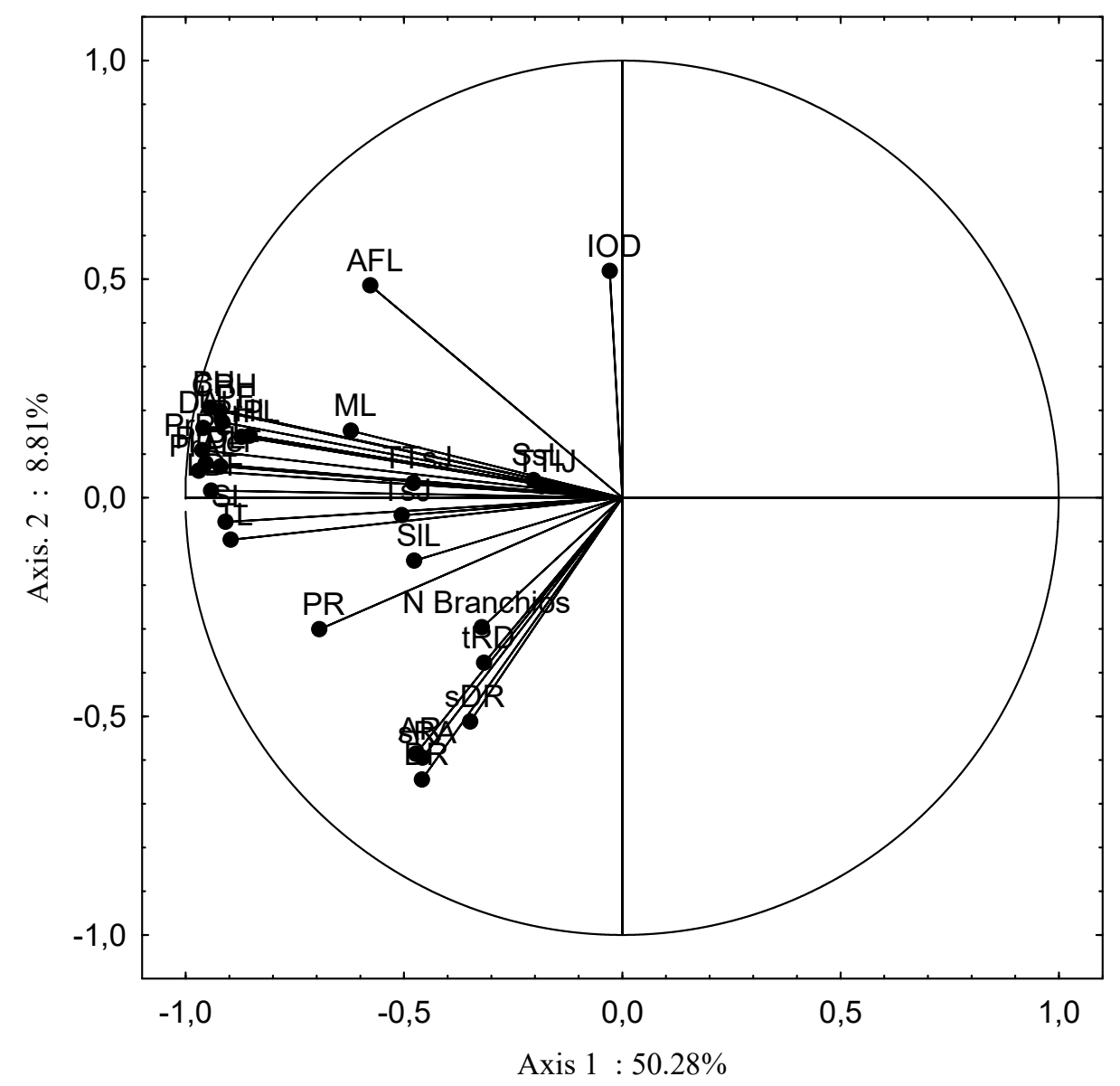

Figure 3: Principal component analysis of metric and meristic variables. 


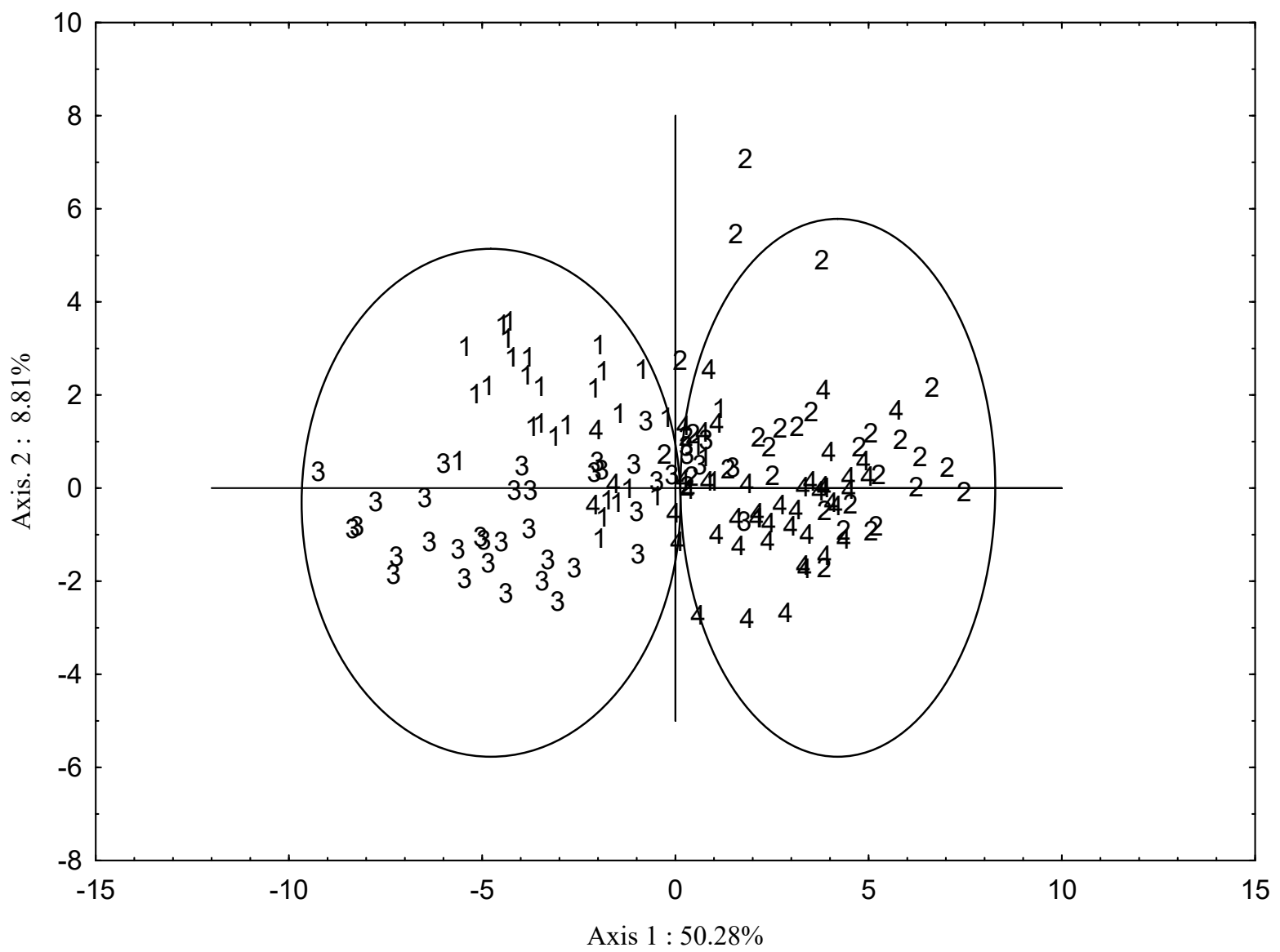

Figure 4: Plot of the Principal components analysis of the metric and meristic variables showing the distribution of Oreochromis niloticus specimens from four localities around Daloa.

\subsubsection{Morphological similarity between} populations: Hierarchical Classification Analysis (HCA) isolated two distinct groups from 1.6 ecludian distance units (Figure 5). The first group consists of Guessabo and PK 12 populations and the second of APDRACI and
Quartier manioc populations. Each group collects specimens from sites with similar morphological characters. This grouping done by the HCA confirms the one presented by the PCA. 


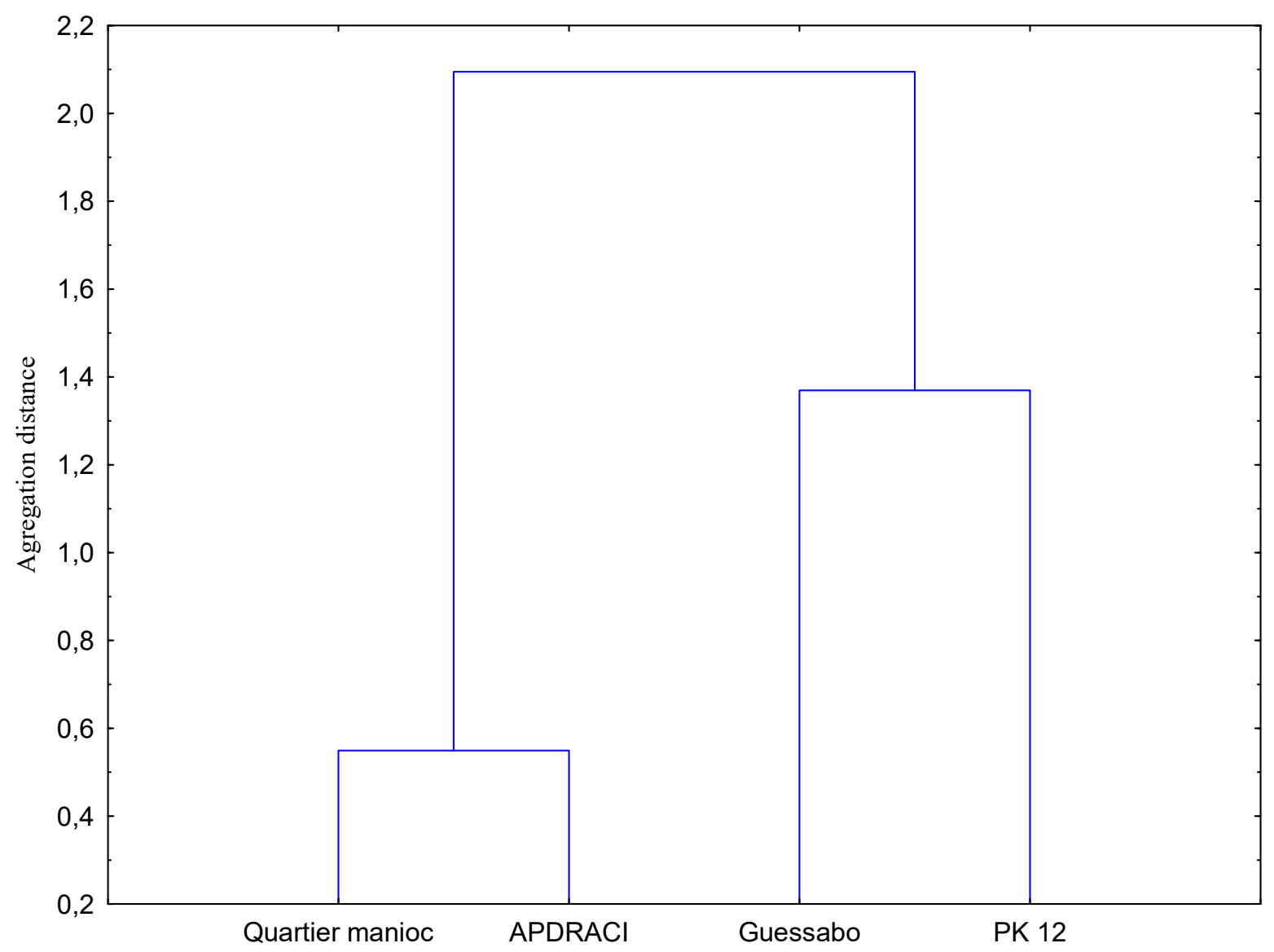

Figure 5: Dendrogram showing the morphological proximities between populations of Oreochromis niloticus.

\subsubsection{Discriminant analysis: Discriminant} analysis revealed that the two groups constituted by the PCA and the HCA (G1 = Guessabo and PK 12 and G2 = APDRACI and Quartier manioc) were differentiated on the basis of six parameters. These most discriminating characters are PrAL. IOD. LDF. DAL. AFL and SsL (Table 3). Of these six characters that distinguished the two groups, the LDF and SsL do not allow complete distinction of groups (Table 4). Group 1. representing Guessabo and PK 12 populations is characterized by the highest values of the four most distinctive variables (LPrA. IOD. DAL and AFL) (Table 4). The discriminant factor analysis (DFA) made on the basis of the six most discriminating characters (PrAL. IOD. LDF. DAL. AFL and SsL) made it possible to constitute two groups (Figure 6) corresponding to the two groups isolated by the PCA and the HCA.

Table 3: Synthesis of the discriminant analysis presenting the variables separating the two groups isolated by the HCA

\begin{tabular}{|lllllll|}
\hline Variables & PrAL & IOD & LDF & DAL & AFL & SsL \\
\hline Probability & 0.029 & 0.000 & 0.000 & 0.000 & 0.019 & 0.006 \\
\hline
\end{tabular}


Table 4: Main characteristics of the different groups

\begin{tabular}{lllllll}
\hline & PrAL & IOD & LDF & DAL & AFL & SsL \\
\cline { 2 - 6 } Group 1 & $11.87 \pm 1.7 \mathrm{a}$ & $1.24 \pm 1.61 \mathrm{a}$ & $7.81 \pm 2.40 \mathrm{a}$ & $8.19 \pm 2.37 \mathrm{a}$ & $2.66 \pm 1.05 \mathrm{a}$ & $21.70 \pm 0.85 \mathrm{a}$ \\
Group 2 & $8.22 \pm 1.37 \mathrm{~b}$ & $0.87 \pm 0.14 \mathrm{~b}$ & $7.19 \pm 1.60 \mathrm{a}$ & $7.36 \pm 1.69 \mathrm{~b}$ & $2.29 \pm 0.51 \mathrm{~b}$ & $21.53 \pm 1.16 \mathrm{a}$ \\
Probability & $<0.001$ & $<0.05$ & 0.06 & $<0.05$ & $<0.05$ & 0.29 \\
\hline
\end{tabular}

For each character. Values with the same letters are statistically equal

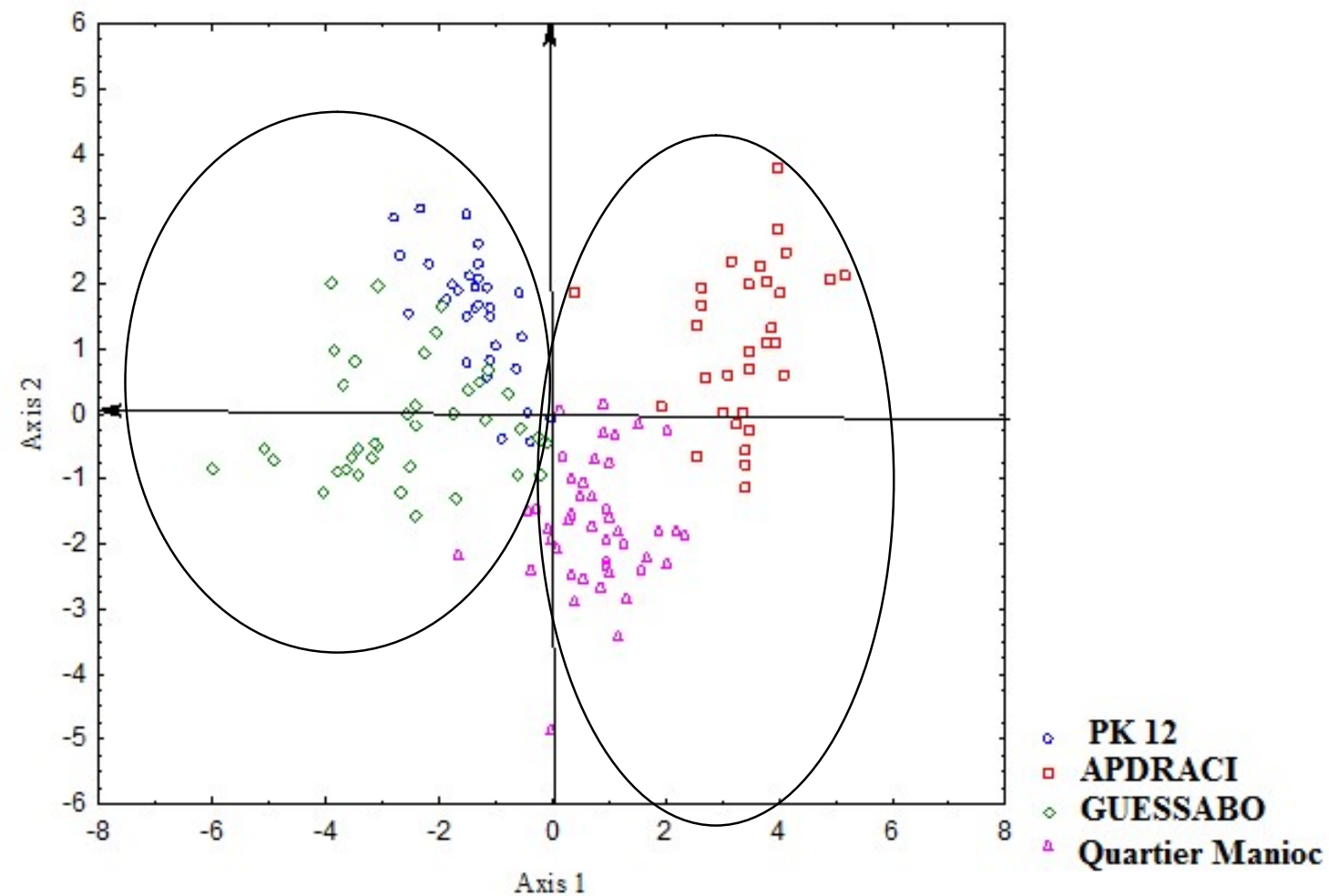

Figure 6: Discriminant factor analysis (DFA) based on discriminant characters

The values recorded in Table 5 give an estimate of the percentage of classification of the defined groups. Groups $1(84.51 \%)$ and 2 $(92.10 \%)$ are very well ranked. Of the 71 and 76

Table 5: Classification Matrix of HCA Groups

\begin{tabular}{llll}
\hline Group & $\%$ Correct & Group 1 & Group 2 \\
\hline Group 1 & 84.51 & 60 & 11 \\
Group 2 & 92.10 & 6 & 70 \\
Total & 88.41 & 66 & 81 \\
\hline
\end{tabular}

individuals group 1 and group 2 respectively, only 11 individuals from group 1 and six individuals from group 2 are misclassified. 


\section{DISCUSSION}

Several tilapia species are traded and farmed, but the species Oreochromis niloticus remains the predominant species of fish farming in the world (FAO, 2009). According to Linnaeus, 1758, several meristic characters characterize this species. This is the number of anal rays, the number of rays in the dorsal, the number of gill rakers on the lower part of the first gill arch. The samples we analyzed present a range of dorsal thoracic rays from 16 to 17 and soft rays from 11 to 15 . These results are in line with those of the FAO, 2009 which places the number of dorsal and soft dorsal rays in the same ranges as those obtained in this study. As for the number of anal rays, the same studies of the FAO place them between 13 and 14 with the number of anal thorny rays equal to 3 and the number of anal soft rays varying between 10 to 11 . This study samples answer well to their limit 3 in relation to the number of anal thorny rays except a slight difference of 7 to 10 obtained in the number of anal soft rays. The number of gill rakers on the first branchial arch obtained (25 to 32), in our study, does not deviate too much from that obtained in FAO (2009) studies (27 to 33). The conformity of these different characters partly reflects the fact that our samples belong to the Oreochromis niloticus species. Of the 31 morphometric characters analyzed, 28 revealed a significant difference between populations $(P<0.05)$. These are ML, LH, PrDL, PrAL, PrPL, PrPeL, IOD, LDF, DAL, BH, CPH, AFL, LPF, LPeF, TL, SL, DR, tRD, sRD, AR, sRA, PR, SsL, SiL, TsJ, TTsJ, TTij and N. branchios. Among these 28 parameters, twenty (20) metric variables in addition to the weight showed a high variability $(\mathrm{CV} \geq 10 \%)$ within the populations. These traits vary from one population to another and suggest that each population consists of a phenotypically heterogeneous group. All the metric variables analyzed showed a strong variation. This large variation in these variables is due to the non-stability of the metric parameters compared to the meristic characters. This variation of these metric characters would be related to the environment. According to Dyne et al. (1999), the variation of some metric descriptors (body height, caudal peduncle height, muzzle length, pectoral fin length) would be phenotypic because of the environment. Principal component analysis (PCA), hierarchical classification analysis (HCA) and discriminant factor analysis (DFA) isolated two groups. One consists of the populations of Guessabo (natural environment) and Kilometer 12 (fish farm located at the end of the city of Daloa) and the other populations of APDRA-CI and Quartier Manioc (two fish farms in the city). Specimens in the first group are characterized by 13 metric characters (HL, PrDL, PrAL, PrPL, PrPeL, DFL, DAL, BH, $\mathrm{CPH}, \mathrm{LPF}, \mathrm{LPeF}, \mathrm{TL}$ and SL) of growth presented by the ACP. Discriminant analysis revealed that the two constituted groups were differentiated on the basis of six parameters. These most discriminating characters are PrAL, IOD, LDF, DAL, AFL and SsL. These descriptors explain the differences observed between the groups. These morphological traits may reflect some of the ecological or behavioral characteristics of fish. Among these most discriminating parameters are the interorbital diameter which could be considered as a key ecological trait related to fish habitat. Thus, according to Schliewen et al., 2001, the diameter of the eye would naturally be subject to selection and therefore inheritable within species groups. Discriminant factor analysis based on the six most discriminating characters (PrAL, IOD, LDF, LAD, AFL and SsL) made it possible to form two groups corresponding to the two groups isolated by the ACP and CAH. Group 1, representing the populations of Guessabo and Kilometer 12, is characterized by the highest values of the four most distinctive variables (PrAL, IOD, LAD and AFL). In this study, the genitors of the PK 12 farm are closer 
to those of the natural environment, Guessabo. The individuals of the Quartier Manioc and APDRA-CI farms are morphologically similar to those of the Quartier Manioc. This distribution is due to the characteristics of the different localities in which the different farms are located. Indeed the farm of PK 12 is located about $7 \mathrm{~km}$ from Dalao city compared to the other farms (APDRA-CI and Quartier Manioc) 6 CONCLUSION

The phenotypic characterization of four populations of Oreochromis niloticus in HautSassandra region, based on 16 metric and 15 meristic characters, revealed that twenty-eight (28) of the 31 morphometric characters studied differentiated populations $(P<0.001)$. Based on these 28 characters, Principal Correspondence Analysis (PCA) and hierarchical classification analysis (HCA) grouped individuals into two groups, one group consisting of Guessabo and PK12 specimens and the other group of APDRA-CI individuals and Quartier Manioc. Six discriminating characters have allowed

\section{REFERENCES}

Azaza MS: 2009. Optimisation de l'élevage intensif du Tilapia de Nil Oreochromis niloticus (L., 1785), dans les eaux géothermales de Sud Tunisien: Effet de l'alimentation et de la température sur les performances de croissance. Thèse de l'Université Tunis Faculté des sciences. Tunis, 364p.

Bookstein FL, Chernoff B, Elder RL, Humphries JrJM, Smith GR. and Strauss RE: 1985. Morphometrics in Evolutionary Biology: the Geometry of Size and Shape Change, with Examples from Fishes Academy of Natural Sciences of Philadelphia, Philadelphia.

Dhraief M, Azaza MS. and Kraiem M: 2010. Etude de la reproduction du Tilapia du Nil Oreochromis niloticus (L) en captivité dans les eaux géothermales du sud tunisien. Bullettin de l'Institut National des which are located in the city. This farm would present the environmental characteristics close to the natural environment of Guessabo. The high percentage of correct classification (84.51\% for group 1 and $92.10 \%$ for group 2$)$ of individuals within the two groups could corroborate differences in habitat affecting morphology differently in each group.

separation these two groups. Those are PrAL. IOD. LDF. DAL. AFL and SsL of these six variables, group 1 (Guessabo and PK 12 populations) is characterized by the highest values of four most distinctive variables (PrAL. IOD, DAL.and AFL). Discriminant factor analysis (DFA) has also classified these populations into two groups identical to those of the PCA and the CAH. The brood stocks of PK 12 farm are morphologically similar to Guessabo specimens. The brood stocks of APDRACI and Quartier Manioc farms are morphologically similar.

Sciences et Technologies de la Mer de Salammbö 37:89-96.

Dyne J, Magnan P, Bernatchez L. and Rodriguez MA: 1999. Genetic and morphological variation between two forms of lacustrine brook charr. Journal of. Fish Biology 54: 955-972.

Elliott NG, Haskard K. and Koslow JA: 1995. Morphometric analysis of orange roughy (Hoplostethus atlanticus) off the continental slope of southern Australia. Journal of Fish Biology 46: 202-220.

FAO: 2016. La situation mondiale des pêches et de l'aquaculture. Contribuer à la sécurité alimentaire et à la nutrition de tous. Rome Italie, 227p.

FAO: 2014. Fisheries and Aquaculture Information and Statistics Service. Rome, Italie, p. 105. 
FAO: 2009. Oreochromis niloticus. In Cultured aquatic species fact sheets. Text by Rakocy, J. E. Edited and compiled by Valerio Crespi and Michael New. CDROM (multilingual).

Ferrito V, Mannino MC, Pappalardo AM. and Tigano C: 2007; Morphological variation among populations of Aphanius fasciatus Nardo, 1827 (Teleostei, Cyprinodontidae) from the Mediterranean. Journal of fish Biology 70 : $1-20$.

Hammer O, Harper DA. and Ryan PD: 2001. Paleontological Statistics Software Package for Education and Analysis. Paleontological Electronica 4 (1):9p.

Hurlbut T. and Clay D. 1998. Morphometric and meristic differences between shallow and deep-water populations of white hake (Urophycis tenuis) in the southern Gulf of St Lawrence. Canadian journal of fisheries and Aquatic Sciences 55: 2274-2282.

Ihssen PE, Booke HE, Casselman JM, McGLADE JM, Payne NR. and Utter FM: 1981. Stock identification: materials and methods. Canadian journal of fisheries and Aquatic Sciences 38: 1838 1855.

Kestemont P, Micha J. et Falter U: 1989. Les méthodes de production d'alevins de Tilapia Nilotica, programme de mise en valeur et la coordination de l'aquaculture. Organisation des Nation Unies pour l'Alimentation et l'Agriculture ADCP/REP/89/46, FAO, Rome. 132p.

Kraiem MM: 1994. Analyse de la variabilité morphométrique et méristique des populations de Barbus callensis, Valenciennes, $1842 \quad$ (Poissons, Cyprinidés) de Tunisie. Bulletin. Français de. Pêche et de Pisciculture 334: 201-212

Lleonart J, Salat J. and Torres GJ: 2000. Removing allometric effects of body size of morphological analysis. Journal of theoretical biology 205:85-93.

Rohlf FJ: 2004. TpsDig Version 1.4. Department of Ecology and Evolution. State University of New York at Stony Brook, New York. http://life.bio.sunysb.edu/morph/inde x.html.

Rohlf FJ: 2006. TpsDig, Digitize Landmarks and Outlines, Version 2.05. Stony Brook, NY: Department of Ecology and Evolution, State University of New York.

Schilewen UK, Rassmann K, Markmann M, Markert J, Kocher and Tautz D: 2001. Genetic and ecological divergence of a monophyletic cichlid species pair under fully sympatric conditions in lake Ejagham, Cameroon. Molecular and. Ecology 10: 1471-1488.

Schneider CA, Rasband WS and Eliceiri KW: 2012. "NIH Image to Image J: 25 years of image analysis". Nature Methods 9:671-675.

Thorpe RS: 1976. Biometric analysis of geographic variation and racial affinities. Biological Reviews 51: 407-452

Zarr JH: 1999. Biostatistical Analysis. $4^{\text {eme }}$ Edition. Prentice-Hall, Englewood Cliffs, New Jersey, 662p.

Zelditch ML, Swiderski DL, Sheets DH. and Fink WL: 2004. Geometric morphometrics for biologist: A primer. http:/www.sciencedirect.com/science/ book/9780127784601. 